\title{
Investigating the effect of organizational capacity on CRM performance
}

\author{
Ahmad Vadadi ${ }^{a}$ and Seyyedeh Fatemeh Farhat Magham ${ }^{b^{*}}$
}

${ }^{a}$ Department of Management and Accounting, Central Tehran Branch, Islamic Azad University, Tehran, Iran ${ }^{b}$ Department of Management and Accounting, South Tehran Branch, Islamic Azad University, Tehran, Iran

\section{H R O N I C L E}

Article history:

Received February 252014

Accepted 17 July 2014

Available online

July 202014

Keywords:

CRM

Commitment

Knowledge about customer

\section{A B S T R A C T}

Many organizations try to provide products with lower prices and better quality to meet their customers' needs by identifying and learning about customers and their needs, and to achieve this important, they need a powerful knowledge tool that relies on customers' knowledge details. This paper presents an empirical investigation to study the effects of organizational capacity on the performance of customer relationship management. The study designs a questionnaire in Likert scale, distributes it among some experts and using structural equation modeling verifies that managers' commitment influences the most on getting knowledge from customer $(\beta=0.389$, Sig. $=0.000)$. In addition, Managers' commitment influences positively on knowledge about customer $(\beta=0.355$, Sig. $=0.000)$. Moreover, Staffs' commitment influences on knowledge about customer $(\beta=0.36$, Sig. $=0.000)$.

\section{Introduction}

Nowadays, competitive advantage is found in process of customer knowledge acquisition and taking competitive markets. Many organizations try to provide products with lower prices and better quality to meet their needs by identifying and learning about customers and their needs, and to achieve this important, they need a powerful knowledge tool that relies on customers' knowledge details. Senior managers' commitment is important in implementing changes in organization, supporting employees and creating commitment among them to obtain and to transfer customer's information and knowledge among staff and make decisions about the way of staff's dealing with the problems according to customer's interests and knowledge. Professional and committed employees who have necessary experience perform customer knowledge sharing in organizations. Creative, committed and motivated employees can change the customers' attitude towards organization and influence on the performance of customer relationship management by providing quality services. Senior managers and employees' commitment provides the organizational capacity and it can improve the performance of customer relationship management with the help of customer knowledge.

*Corresponding author.

E-mail addresses: Farnaz_Farhat@yahoo.com (S.F. Farhat Magham) 
Organizational capacity, investigated from two aspects of managers and staffs' commitment, is an important organizational and occupational attitude. Over the past years, organizational capacity has been a favorite concept for many researchers of management science. Organizational capacity is associated with the role of senior managers in implementing changes in organization, supporting for its implementation, and leadership throughout the implementation process. It also includes staffs' commitment needed for implementing processes, interacting with customers and their role in the effective implementation of the programs.

Commitment includes is normally defined as to accept the action, to maintain and to make the pledge. Therefore, commitment means that a person invests in an organization and does not leave the organization. Senior manager is the main person in development process and support commitments. A manager can be effective in organization, its staffs, functions and customers by embracing a commitment as a positive force. Privileged managers recognize that their duty is to make commitment toward client, organization, key tasks of individuals and themselves. For making this commitment, they should create appropriate attitudes and represent a positive interest. This action is the duty of every employee and not the manager's duty. Making commitment is accomplished by help of dedication and service. When senior manager is really faithful toward his/her subordinates, subordinates show fortitude and commitment toward their duties. Senior manager has five key commitments according to Hersey and Blanchard (1969):

- Senior manager's commitment to customer: The first and maybe the most important organizational commitment on customer emphasizes on privileged managers who try to provide useful services for customers.

- Commitment to the organization: The second manager's commitments emphasize on organization and show this commitment by three ways: reputing organization, supporting the senior management, and acting to main values of organization.

- Senior manager's commitment to himself: the third commitment relies on manager; managers have a strong and positive image of themselves for others. They act as a strong power in all situations. Commitment itself is turned out of three specific activities: demonstrating autonomy, consolidating his positions as a manager and accepting constructive criticism.

- Manager's commitment to individuals: the forth manager's commitment emphasizes on teamwork and every member of the group; managers show devotion to who works for them. This action refers to manager's use of correct leadership in order to help people succeed in accomplishing their duties. There are three critical actions of components of this commitment: demonstrating positive interest, giving development feedback, encouraging innovative ideas.

- Manager's commitment to duty: the fifth manager's commitment relies on duties that must be performed. Successful managers give meaning to duties done by staffs; they determine the spotlight and direction for staffs and guarantee to do their assignments, successfully.

If these five commitments are executed continuously, the effective manager emerges. Manager is a link among each of commitment. Peltier et al. (2013) developed and examined an organizational learning framework of the relationship between organizational processes, customer data quality and firm performance. They reported that high quality customer data could influence on both customer and business performance and that the most important driver of customer data quality came from the executive suite. A large portion of the effect of organizational culture on performance was mediated by customer data quality and data sharing. The results of their survey have also supported the presence of a hierarchy of effects for enhancing data quality that runs from organizational learning to cross-functional learning to functional learning. 
Alshawi et al. (2011) identified the organizational, technical and data quality related factors impacting customer relationship management (CRM) adoption by SMEs. The study enhanced the quality of the evaluation process, and helped support SME decision makers in exploring the implications surrounding CRM adoption. The findings of this study confirmed that factors influencing the adoption of CRM in SMEs were largely similar to the factors influencing CRM adoption in previously studied other types of organizations.

Chang et al. (2010) investigated the process concerning how CRM technology could translate into business outcomes. They reported that marketing capability could mediate the association between CRM technology use and performance. In addition, a customer-centric organizational culture and management system could facilitate CRM technology implementation. The study served not only to clarify the mechanism between CRM technology use and organizational performance, but also to generalize the CRM results in the Korean context.

Steel et al. (2013) studied the effect of industry, organizational, and customer context on CRM projects. Organizations go through four phases in their CRM projects but there are few studies on the effect of industry norms, organizational contexts, and customer expectations on each phase. They used a longitudinal case study approach with six cases to study the potential effect of contextual factors on CRM projects. The cases covered a range of industries, organizational structures, and customer types. They reported that current industry conditions and customer expectations could impact the reasons for undertaking CRM and the assessment stage of the project. The organizational context, in this study, had a remarkable effect on the design and implementation project stages. At the evaluation level, customer responses combined with organizational expectations could influence on the perceived success of the projects.

Garrido-Moreno and Padilla-Meléndez (2011) reported that many studies that analyze the essential role played by knowledge management $(\mathrm{KM})$ could be considered as determinants of the success of CRM. They examined the relationships between KM and CRM success using a structural equation model. The main contribution was that having knowledge management capabilities was not enough for the success of CRM, but there were other factors to consider. More specifically, organizational factors indeed influence CRM success and they appeared to be intermediaries of the effect of other factors for the success of CRM.

Becker et al. (2009) proposed a conceptual model, which studies the link between technological and organizational implementations, as well as the implementations' interactions with management and employee support and CRM process-related performance. By computing CRM performance in terms of the initiation, maintenance, and retention of customer relationships, they provided a detailed picture of what CRM implementations were capable of achieving. The results of the empirical study, conducted across four industries and ten European countries, showed that CRM implementation did not influence on performance equally for various aspects of the CRM process, and that it had an effect only if supported by the appropriate firm stakeholders.

Trainor et al. (2014) studied how social media technology usage and customer-centric management systems could contribute to a firm-level capability of social CRM. Drawing from the literature in marketing, information systems, and strategic management, the first contribution of this study was the conceptualization and measurement of social CRM capability. In addition, they examined how social CRM capability was influenced by both customer-centric management systems and social media technologies. These two resources were determined to have an interactive impact on the formation of a firm-level capability shown to positively associated with customer relationship performance.

\section{Research methodology}

The proposed study of this paper investigates the effects of employees and managers' commitment on knowledge about/for customers. It also investigates the effects of knowledge about/for/from 
customers on customer relationship management. Fig. 1 demonstrates the structure of the proposed study.

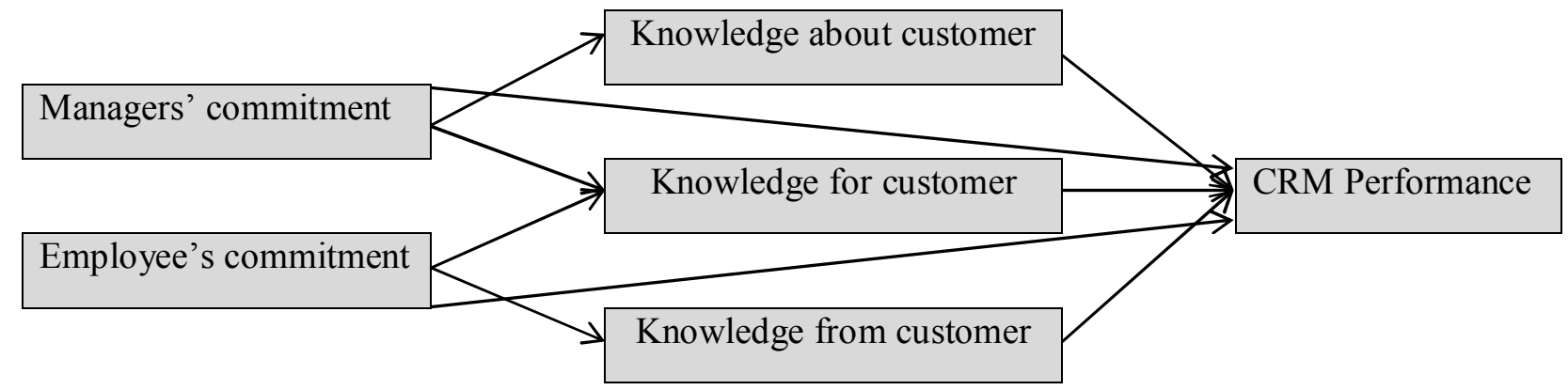

Fig. 1. The structure of the proposed study

Since the research is accomplished with purpose of application of finding results for solving a particular problem within organization, in terms of purpose is practical and in terms of method is menstruation. In this study, statistical population includes all 150 senior managers and senior specialists of Tejarat Bank in Iran. Therefore, the sample size is calculated as follows,

$$
n=\frac{N \times z_{\alpha / 2}^{2} \times p \times q}{\varepsilon^{2} \times(N-1)+z_{\alpha / 2}^{2} \times p \times q},
$$

where $N$ is the population size, $p=1-q$ represents the yes/no categories, $z_{\alpha / 2}$ is CDF of normal distribution and finally $\varepsilon$ is the error term. Since we have $p=0.5, z_{\alpha / 2}=1.96$ and $N=150$, the number of sample size is calculated as $n=109$. In this study structural equation modeling is used to verify the hypotheses of the survey. Table 1 demonstrates the results of Kolmogorov-Smirnov test.

Table 1

The results of Kolmogorov-Smirnov test
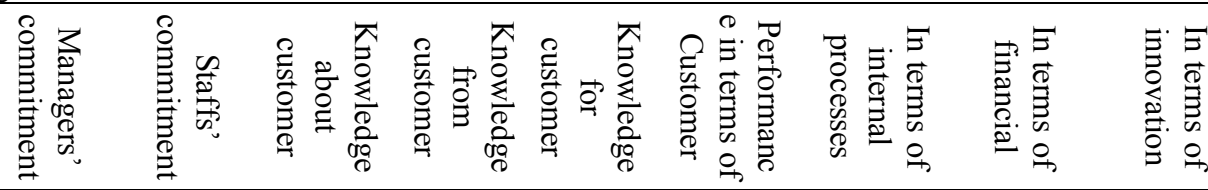

\begin{tabular}{ccccccccccc}
\hline \multicolumn{2}{c}{ Number } & 109 & 109 & 109 & 109 & 109 & 109 & 109 & 109 & 109 \\
\hline $\begin{array}{c}\text { Normal } \\
\text { parameters }\end{array}$ & Average & 3.8055 & 3.7313 & 3.4664 & 3.6560 & 3.7125 & 3.5468 & 3.7775 & 3.6537 & 3.5963 \\
& $\begin{array}{c}\text { Standard } \\
\text { deviations }\end{array}$ & .75594 & .70301 & .69381 & .64441 & .76909 & .66145 & .58934 & .72402 & .72561 \\
\hline \multirow{2}{*}{$\begin{array}{c}\text { The most } \\
\text { differences }\end{array}$} & $\begin{array}{c}\text { Absolute } \\
\text { value }\end{array}$ & .134 & .140 & .087 & .116 & .102 & .080 & .083 & .098 & .087 \\
& Positive & .064 & .045 & .056 & .077 & .102 & .056 & .083 & .098 & .087 \\
\hline $\begin{array}{c}\text { Kolmogorov - } \\
\text { Smirnov Statistics }\end{array}$ & -.134 & -.140 & -.087 & -.116 & -.095 & -.080 & -.082 & -.095 & -.080 \\
\hline \multicolumn{2}{c}{ Meaningful test } & .051 & .058 & .383 & .106 & .208 & .490 & .441 & .248 & .379 \\
\hline
\end{tabular}

As we can observe from the results of Table 1, all components of the survey are normally distributed when the level of significance is five percent.

For testing different hypotheses, structural equation modeling (SEM) are used and the results of our survey are summarized in Table 2 as follows, 
Table 2

Coefficients of conceptual model path

\begin{tabular}{lccc}
\hline Path & $\beta$ & $\mathrm{T}$ & Result \\
\hline Managers' commitment $\rightarrow$ knowledge about customer & 0.355 & 3.73 & Confirmed \\
Staffs' commitment $\rightarrow$ knowledge about customer & 0.36 & 4.4 & Confirmed \\
Managers' commitment $\rightarrow$ knowledge from customer & 0.389 & 3.85 & Confirmed \\
Staffs' commitment $\rightarrow$ knowledge from customer & 0.07 & 0.69 & Rejected \\
Managers' commitment $\rightarrow$ knowledge for customer & 0.07 & 0.56 & Rejected \\
Staffs' commitment $\rightarrow$ knowledge for customer & 0.2 & 2.74 & Confirmed \\
Managers' commitment $\rightarrow$ Customer relationship management & 0.186 & 2.66 & Confirmed \\
Staffs' commitment $\rightarrow$ Customer relationship management & 0.125 & 2.45 & Confirmed \\
Knowledge about customer $\rightarrow$ Customer relationship management & 0.281 & 3.63 & Confirmed \\
Knowledge from customer $\rightarrow$ Customer relationship management & 0.117 & 2.14 & Confirmed \\
Knowledge for customer $\rightarrow$ Customer relationship management & 0.299 & 3.7 & Confirmed \\
\hline$R^{2}$ For knowledge for customer & 0.06 & $Q^{2}$ For knowledge for customer & 0.08 \\
$R^{2}$ For knowledge from customer & 0.187 & $Q^{2}$ For knowledge from customer & 0.2 \\
$R^{2}$ For knowledge about customer & 0.381 & $Q^{2}$ For knowledge about customer & 0.31 \\
$R^{2}$ Customer relationship management performance & 0.536 & $Q^{2}$ Customer relationship management & 0.43 \\
\hline
\end{tabular}

As we can observe from the results of Table 2, only the effects of staff as well as managers' knowledge from/for customer were not confirmed and the effects of other components have been firmed when the level of significance is five percent. In our survey, managers' commitment influences the most on getting knowledge from customer $(\beta=0.389$, Sig. $=0.000)$. In addition, Managers' commitment influences positively on knowledge about customer $(\beta=0.355$, Sig. $=0.000)$. Moreover, Staffs' commitment influences on knowledge about customer $(\beta=0.36$, Sig. $=0.000)$.

\section{Discussion and conclusion}

In this paper, we have presented an empirical investigation to study the effects of organizational capacity on performance of customer relationship management in Iranian banking industry. The study has implemented structural equation modeling and it has confirmed that knowledge about/for customer influenced positively on CRM. In addition, the study has disclosed that employee as well as managers' commitment could influence positively on knowledge for/from customers. While managers' commitment influenced positively on knowledge about customer, only the effect of managers' commitment on knowledge from customer was approved.

\section{Acknowledgement}

The authors would like to thank the anonymous referees for constructive comments on earlier version of this paper.

\section{References}

Alshawi, S., Missi, F., \& Irani, Z. (2011). Organisational, technical and data quality factors in CRM adoption-SMEs perspective. Industrial Marketing Management, 40(3), 376-383.

Becker, J. U., Greve, G., \& Albers, S. (2009). The impact of technological and organizational implementation of CRM on customer acquisition, maintenance, and retention. International Journal of Research in Marketing, 26(3), 207-215.

Chang, W., Park, J. E., \& Chaiy, S. (2010). How does CRM technology transform into organizational performance? A mediating role of marketing capability. Journal of Business Research, 63(8), 849855.

Garrido-Moreno, A., \& Padilla-Meléndez, A. (2011). Analyzing the impact of knowledge management on CRM success: The mediating effects of organizational factors. International Journal of Information Management, 31(5), 437-444.

Hersey, P., \& Blanchard, K. H. (1969). Life cycle theory of leadership. Training \& Development Journal, 23(5), 26-34. 
Peltier, J. W., Zahay, D., \& Lehmann, D. R. (2013). Organizational learning and CRM success: a model for linking organizational practices, customer data quality, and performance. Journal of Interactive Marketing, 27(1), 1-13.

Steel, M., Dubelaar, C., \& Ewing, M. T. (2013). Developing customised CRM projects: The role of industry norms, organisational context and customer expectations on CRM implementation. Industrial Marketing Management, 42(8), 1328-1344.

Trainor, K. J., Andzulis, J. M., Rapp, A., \& Agnihotri, R. (2014). Social media technology usage and customer relationship performance: A capabilities-based examination of social CRM. Journal of Business Research, 67(6), 1201-1208. 